\title{
Cytological Studies on the Enterochromaffin Cells in the Intestinal Metaplasia*
}

\author{
Akira Nabeyama and Takuro Ogata \\ Department of Surgery $\dagger$ \\ Okayama University Medical School, Okayama
}

\begin{abstract}
NabeYama, A. and OGata, T. Cytological Studies on the Enterochromaffin Cells in the Intestinal Metaplasia. Tohoku J. exp. Med., 1971, 105 (4), 355-363 The enterochromaffin cells (Ec-cells) in the normal and pathological antral mucosa of the human stomach were examined. It was clarified that the Ec-cells are observed only in the mucosa with intestinal metaplasia, and never in the normal mucosa. We tentatively classified the Ec-cells into two types: Ec-I-cells and Ec-II-cells. The specific granules in the Ec-I-cells are polymorphous and contain a dense core enclosed by a limiting membrane which fits either tightly or loosely. The Ec-II-cells have electron dense and polymorphous granules but do not contain a dense core in the limiting membrane. The ratio of Ec-Icells to Ec-II-cells in the antral mucosa with intestinal metaplasia seems to be almost equal in gastric ulcer but smaller in gastric cancer. We propose the hypothesis that the endocrine cells in antral mucosa are changed into intestinal types of endocrine cells in the course of development of the intestinal metaplasia.

- enterochromaffin cells; gastric mucosa; gastric ulcer; gastric cancer
\end{abstract}

Recently, ultrastructural and histochemical studies of the gastrointestinal tract have become to be focussed on the endocrine cells. Kurosumi et al. (1958) first described the ultrastructural appearance of the argentaffin cell in the gastric mucosa of the rat. We reported 5 to 7 types of endocrine cells in the normal antropyloric mucosa of the human stomach (Ogata et al. 1970, Nabeyama et al. 1971). Rubin (1969), Pearse et al. (1970) and Kobayashi et al. (1970) also reported on the endocrine cells of the gastrointestinal mucosa in different clinical states. The present paper reports on the optical and electron microscopic studies carried out on the Ec-cells in the antral mucosa obtained from different clinical states.

\section{Materials and Methods}

Tissue specimens were obtained from the normal and pathological antrums of the 27 adult patients ( 5 cases of gastritis, 5 cases of gastric polyp, 12 cases of gastric ulcer and 5 cases of gastric cancer) 3 to $4 \mathrm{~cm}$ proximal to the pyloric ring after gastric resection or during operation, and immediately fixed for 24 hours in cold $4 \%$ glutaraldehyde in Millonig's buffer, $\mathrm{pH}$ 7.4. After repeated rinses in $0.2 \mathrm{M}$ phosphate buffer, $\mathrm{pH} 7.4$, the

Received for publication, May 6, 1971 .

$\uparrow$ Director: Prof. S. Tanaka.

* This study was reported at the 57th Congress of the Japanese Society of Gastroenterology in Tokyo (April 4, 1971). 
tissue pieces were postfixed in $2 \%$ osmium tetroxide in the same buffer. After dehydration in alcohol, the tissues were embedded in Epon 812. Thick sections were stained with uranyl acetate followed by lead hydroxide and examined under a Hitachi HU-II electron microscope.

\section{RESUlts}

Many specimens of antral mucosa stained with toluidine blue were first examined under the optical microscope. In general, the Ec-cells in the antral mucosa with intestinal metaplasia have granules deeply stained with toluidine blue in the infranuclear region (Figs. 2 and 3). The Ec-cells are scattered among the goblet cells and intestinal cells and are detected mainly in the deeper layer of the intestinalized mucosa. It has been considered that the Ec-cells are common in the duodenum, moderate in the stomach, and relatively rare in the jejunum and ileum except for the appendix, where they occur in considerable numbers. The present optical microscope study demonstrated that the Ec-cells occurred in considerable numbers in the antral mucosa with intestinal metaplasia and were not found in the normal antral mucosa (Fig. 1).

These Ec-cells were examined with the electron microscope. It was elucidated that two types of Ec-cells might exist in the antral mucosa with intestinal metaplasia. One has specific granules which are electron dense and polymorphous in shape, and has a dense core enclosed by a limiting membrane which fits either tightly or loosely (Figs. 4 and 6). These cells have been tentatively called Ec-I-cells. Another type of Ec-cell is that called the Ec-II-cell in this paper. The Ec-II-cells are in contact with the basement membrane. The cytoplasm is less dense than that of the surrounding cells. The organellas in the cytoplasm have some features resembling those of the Ec-I-cell. The specific granules in the Ec-II-cell are also situated in the lower part of the cytoplasm. These granules are electron dense and polymorphous: kidney-shaped and rod-like; moreover, they are homogeneous, that is, they do not contain a dense core. Microfilaments in the apex and around the nucleus are prominent in the Ec-II cell, especially in gastric cancer (Fig. 7). The mitochondria in the apical part are quite numerous and are moderately so in other parts of the cytoplasm. The ratio of the Ec-I-cells to the Ec-II-cells in the antral mucosa with intestinal metaplasia seems to be almost equal in gastric ulcer, but smaller in gastric cancer.

\section{Discussion}

The Ec-cells were deeply stained with toluidine blue and well demonstrated in the intestinalized antral mucosa (Fig. 2). In a previous paper of ours (1971) we included the Ec-cell in the group of normal stomach endocrine cells. However, in the present study we are convinced that Ec-cells do not occur in the normal antral mucosa, but only in the intestinalized antral mucosa.

The granules of the type-I-cell, the so-called Ec-cell in a previous paper of ours (1971), are polymorphous in shape and electron dense, and some of them have an electron dense core within a limiting membrane. 
Forssmann et al. (1969) reported Ec-cells in the rat duodenal mucosa, the granules of which are polymorphous in shape and electron dense; these cells consisted of a homogeneous, electron-opaque substance tightly surrounded by a membrane. Several ultrastructural studies (Toner 1964), Carvalheira et al. 1968, and Kobayashi et al. 1970) in various species and organs have been reported. It has been generally accepted that the features of the granules in the Ec-I-cell are polymorphous and electron dense. The Ec-II-cell in this paper has at least two distinct differences in ultrastructure from the Ec-I-cell. One of the features is that granules have no core within their limiting membrane, namely they have no electron translucent space between the granule and the limiting membrane, and the other is that microfilaments are prominent in the cytoplasm, especially around the nucleus and in the apex. The microfilaments in the Ec-II-cell are particularly outstanding, especially in the case of gastric cancer. Kobayashi et al. (1970) and Sasagawa et al. (1970) reported on the Ec-cells in the human duodenum and stomach that the Ec-cells in the human stomach are relatively few, in a striking contrast to their rich population in the duodenum. Through the examination of many normal and pathological specimens of antral mucosa, it was clarified that the Ec-I-cell and Ec-II-cell are originally attributable to the intestinal mucosa. The occurrence of Ec-I-cells and Ec-II-cells in the antral mucosa with intestinal metaplasia suggests that the endocrine cells in the human stomach may be changed into types of intestinal endocrine cells with the progress of intestinal metaplasia. However, some problems still remain to be solved as to how other endocrine cells, which have been observed in the normal antral mucosa, would behave in the pathological mucosa. Further studies in this direction are in progress.

\section{Acknowledgment}

We wish to express our thanks to Prof. S. Tanaka for his advice and encouragement, and to Mr. T. Nakamura, Mr. N. Hayashi, Mr. N. Saihara, Miss K. Shigezane and Miss $\mathrm{S}$. Hirose for their technical assistance.

\section{References}

1) Carvalheira, A.F., Welsch, U. \& Pearse, A.G.E. Cytochemical and ultrastructural observations on the argentaffin and argyrophil cells of gastrointestinal tract in mammals, and their place in the APUD series of polypeptide-secreting cells. Histochemie, 1968, 14, 33-46.

2) Forssmann, W.G., Orci, L., Pictet, R., Renold, A.E. \& Rouiller, C. The endocrine cells in the epithelium of the gastrointestinal mucosa of the rat. An electron microscope study. J. Cell Biol., 1969, 40, 692-715.

3) Kobayashi, S., Fujita, T. \& Sasagawa, T. The endocrine cells of human duodenal mucosa. An electron microscope study. Arch. histol. jap., 1970, 31, 477-494.

4) Kurosumi, K., Shibasaki, S., Uchida, G. \& Tanaka, Y. Electron microscope studies on the gastric mucosa of normal rats. Arch. histol. jap., 1958, 15, 587-624.

5) Nabeyama, A., Murata, F., Matsuda, H. \& Ogata, T. Ultrastructural classification of endocrine-like cells in the mucosa of human stomach. Tohoku J. exp. Med., 1971, $103,17-47$.

6) Ogata, T., Nabeyama, A., Murata, F. \& Matsuda, H. An electron microscopic study 
on the endocrine-like cells in the mucosa of the human stomach. Jap. J. Clin. Electron Microscopy, 1970, 3, 621-622.

7) Pearse, A.G.E., Coulling, I., Weavers, B. \& Friesen, S. The endocrine polypeptide cells of the human stomach, duodenum, and jejunum. Gut, 1970, 11, 649-658.

8) Rubin, W. Proliferation of endocrine-like (enterochromaffin) cells in atrophic gastric mucosa. Gastroenterology, 1969, 57, 641-648.

9) Sasagawa, T., Kobayashi, S. \& Fujita, T. The endocrine cells in the human pyloric antrum. An electron microscope study of biopsy materials. Arch. histol. jap., 1970, 275-288.

10) Solcia, E., Vassallo, G. \& Sampietro, R. Endocrine cells in the antro-pyloric mucosa of the stomach. $Z$. Zellforsch., 1967, 81, 474-486.

11) Toner, P.G. Fine structure of argyrophil and argentaffin cells in the gastro-intestinal tract of the fowl. Z. Zellforsh., 1964, 63, 830-839.

Fig. 1. Light micrograph of the normal antral mucosa. Numerous endocrine cells (arrows) are observed in the normal antral mucosa, especially near the bases of the glands. Ec-cells are not contained in these endocrine cells, identity being verified by electron microscopic study of thin sections. $\times 1,200$.

Fig. 2. Light micrograph of the intestinalized antral mucosa. Ec-cells (arrows) which contain the granules deeply stained with toluidine blue at the infranuclear region are observed among the intestinalized epithelium. GL: goblet cell. $\times 1,200$.

Fig. 3. Light micrograph of the deeper laye- of the duodenal mucosa. Ec-cell (arrow) is observed among the duodenal mucosa. $\times 1,200$. 


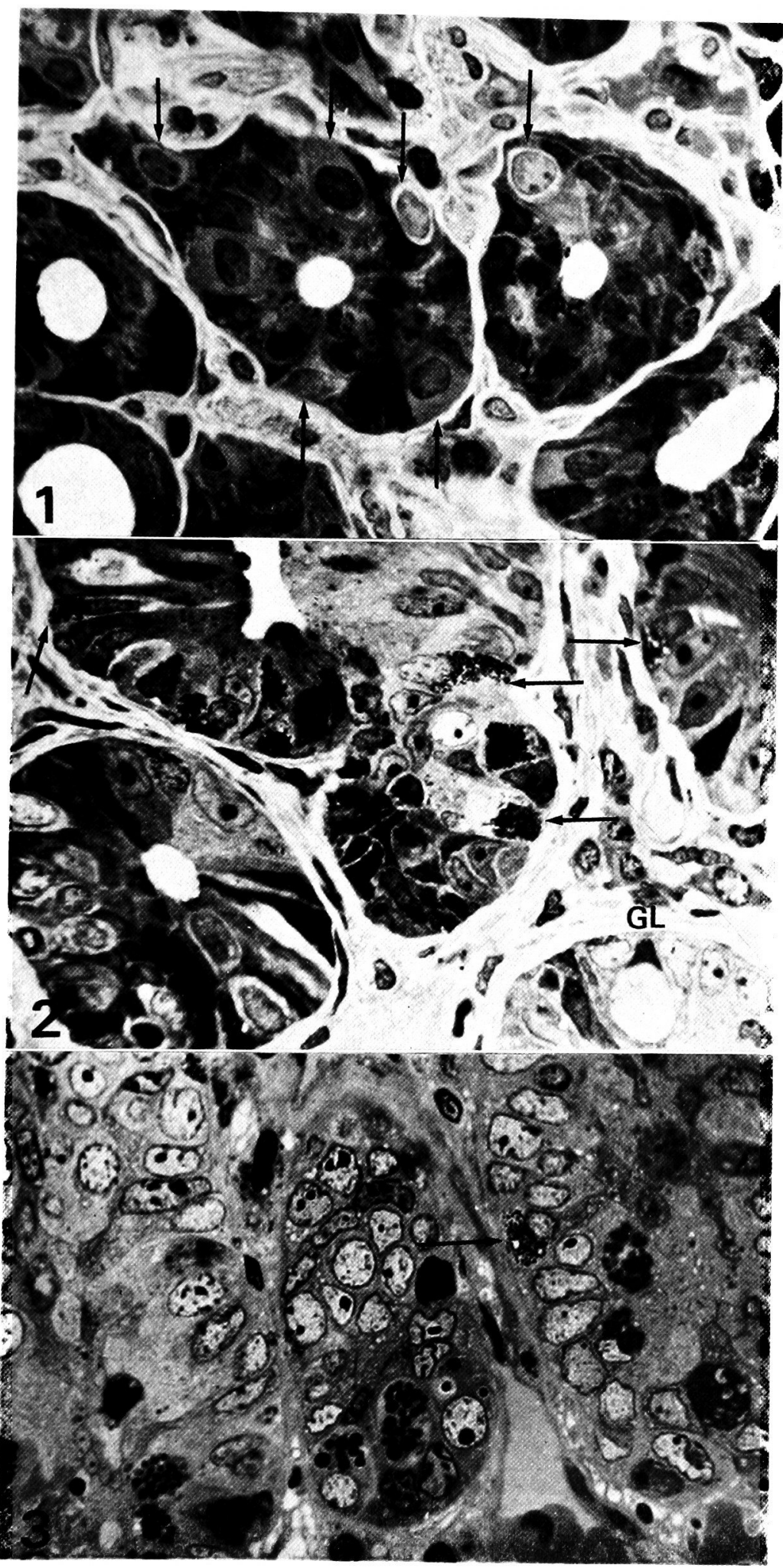


Fig. 4. Electron micrograph of Ec-I-cell. Many electron dense granules are found at the infranuclear region. MV: microvilli. $\mathrm{N}$ : nucleus. $\times 7,000$.

Fig. 5. Electron micrograph of the Ec-II-cell. Many electron dense and polymorphous granules are found in the infranulear region. They have no dense core in the granules $(G) . \times 11,000$. 


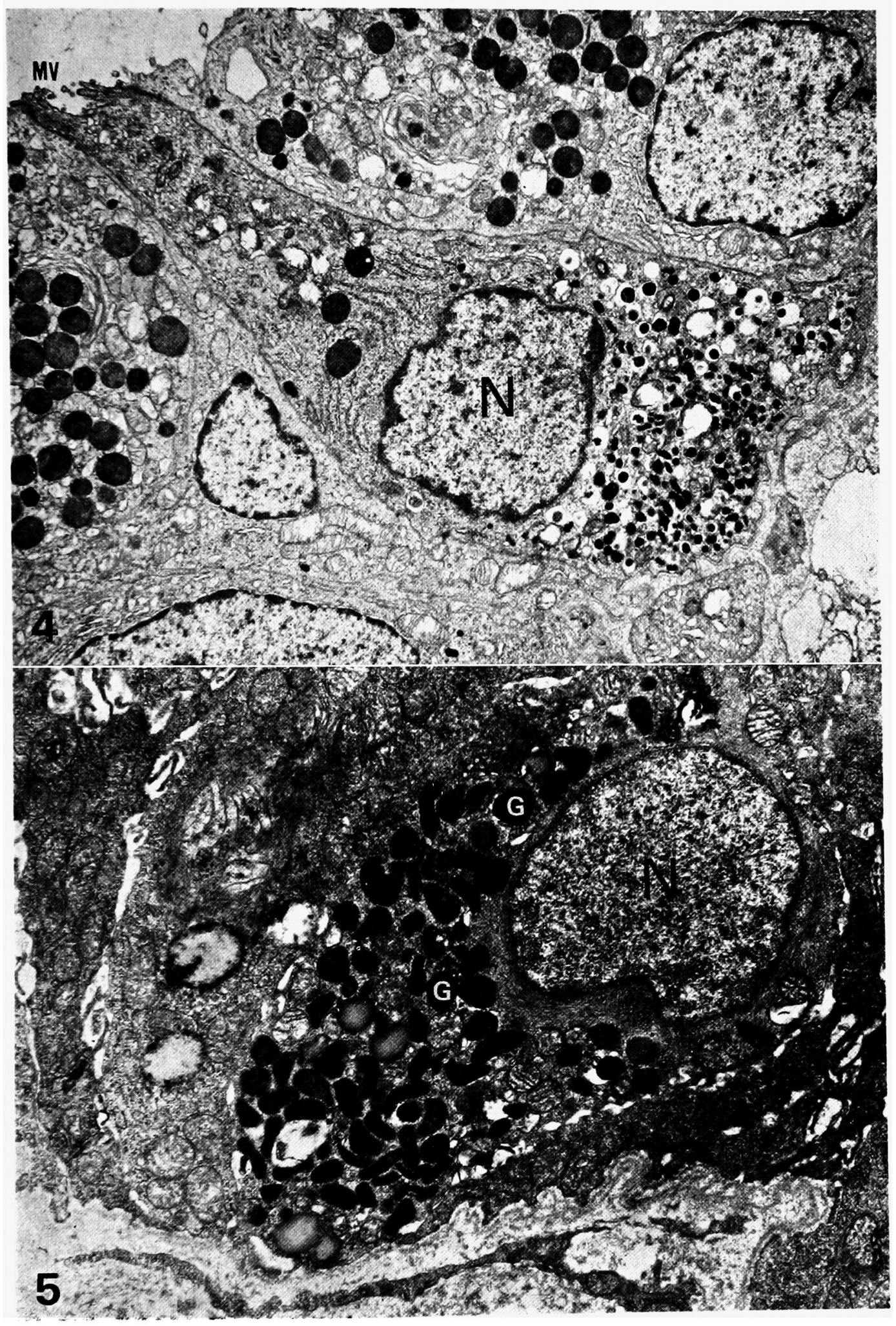


Fig. 6. Higher magnification of a part of the Fig. 4. The granules in the Ec-I-cell have a membrane enclosed denes core. GC: granule with a core. BM: Basement membrane. $\times 33,000$.

Fig. 7. Higher magnification of a part of Fig. 5. Note the prominent microfilaments around the nucleus. F: microfilament. G: granule. MT: mitochondria. N: nucleus. $\times 31,000$ 


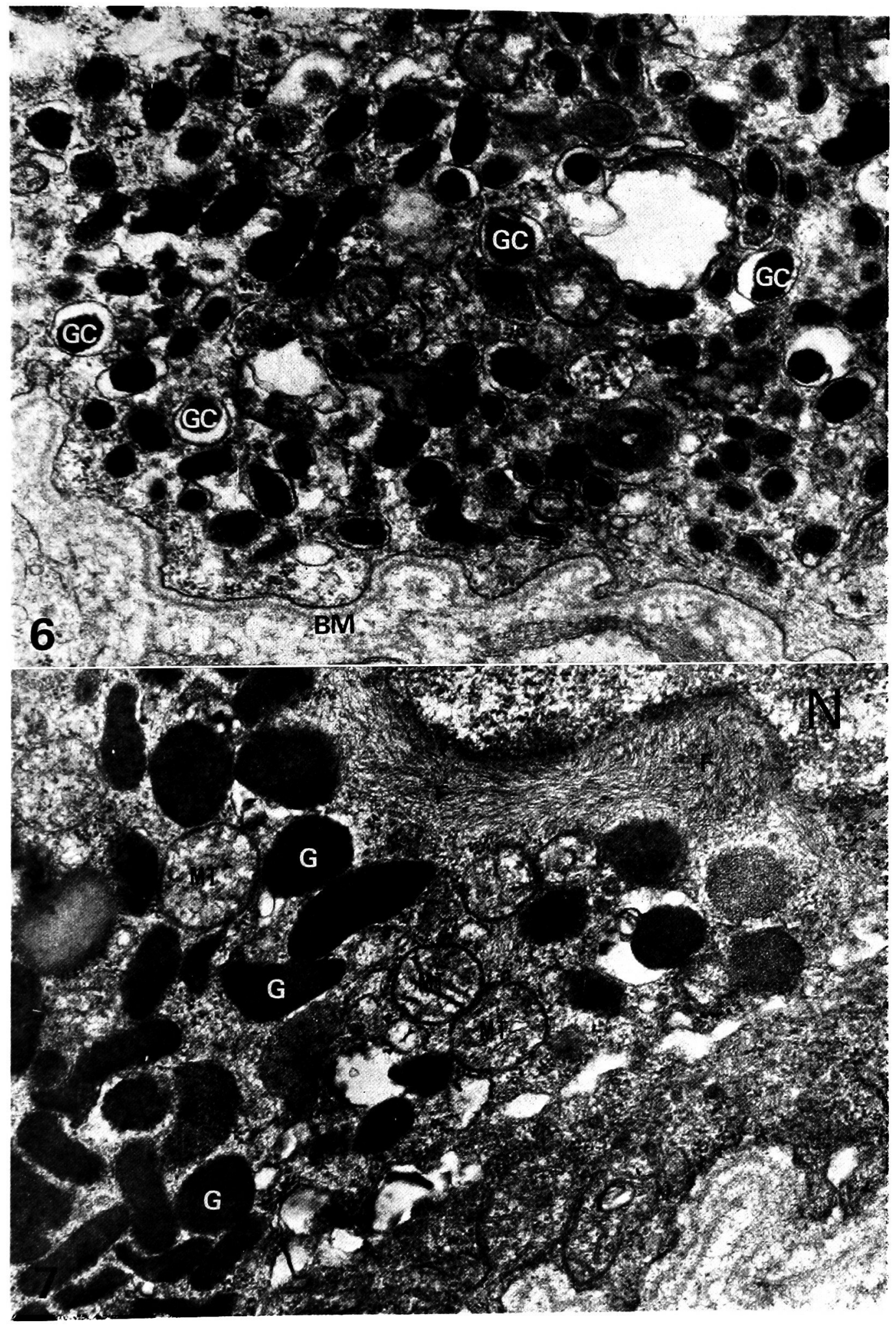

